\title{
Neuro Linguistic Programming Psychotherapy for Improving Emotional State: A Pilot Study
}

\author{
Article by Chetna Punia \\ Msc Psych Texila American University, India \\ Email: chetna.punia@gmail.com
}

\begin{abstract}
This pilot study was conducted for assessing efficacy of Neuro Linguistic Programming Psychotherapy in improving emotional state. NLP psychotherapy techniques used were timeline, anchoring, double dissociation, perceptual positions, reframing, metaphors, strategy change and values elicitation. NLP Psychotherapy session(s) were given to ten participants $(N=10)$ six females and four males. Methods for data collection included personal interviews, participant's experiential report, DASS (Depression Anxiety Stress Scale) and NLP wheel of life scale. Assessment of emotional state change was done on Pre and post therapy scores of DASS (Depression Anxiety Stress Scale) and NLP wheel of life scale along with changes in experiential report of participants before and after therapy session(s). Results obtained by t-tests performed on DASS scores found statistically significant $(p<0.001)$ improvement for all three categories of emotional state i.e. stress, anxiety and depression. Improvement on wheel of life scale score and subjective experience of participants was also reported suggesting that NLP Psychotherapy could improve emotional state in fewer sessions. This pilot study shows positive outcome and also adds to the sporadic literature of NLP psychotherapy as an evidence based study supported by significant statistical findings, subjective experiential improvement in emotional state of participants with up to six months follow up noting stability of resourceful changes attained.

Keywords: Neuro Linguistic Programming, Psychotherapy, Emotional State

\section{Neuro Linguistic Programming Psychotherapy for Improving Emotional State}

Integrated Neuro Linguistic Programming and personal encounter psychotherapy is found useful for making fundamental changes quickly and effectively (Bolstad R, 2002). (Gray R M Liotta R F, 2012) noted long term efficacy, speed of operation and possibility of being run content free of Visual kinesthetic dissociation protocol or rewind technique for Post traumatic stress disorder. (Wake L, Leighton M, 2014) suggests NLP's potential as a therapeutic tool in the treatment of symptoms of anxiety and depression associated with self report of PTSD and observed statistically significant $(\mathrm{p}<0.001)$ improvement in candidates' emotional state measured on three DASS (Depression, Anxiety and Stress) categories. Assertiveness skills training program of NLP strategies is reported to be highly effective in reducing state anger in a control investigation, (Tabrizi F, Shafiabadi F, Zahrakar K, 2015) consisting of a group of married women admitted to home health.

The term NLP (Neuro Linguistic Programming) was coined by Bandler and Grinder, refers to use of language of mind to consistently achieve one's specific and desired outcomes. Neuro- the nervous system (the mind) through which our internal experience is processed through five senses : visual, auditory, kinesthetic, olfactory and gustatory; Linguistic- includes language (verbal and non verbal) through which we communicate with outside and inside world and give meaning like pictures, sounds, feelings, tastes, smells and self talks; Programming- It is the ability to discover and utilize the programs (one's communication to self and others) that we run in our neurological
\end{abstract}


South American Journal of Academic Research

Special Edition May 2016

systems to achieve specific desired outcomes. (McWhirter, 1992) defined it as "the study of the structure of subjective experience".

NLP as a theory draws from a wide range of sources and within NLP influences from Gestalt therapy (Perls, 1969), person centered counselling (Rogers, 1961), transformational grammar (Grinder and Elgin, 1973), behavioral psychology and cybernetics (Ashby, 1965), the Palo Alto school of brief therapy (Watzlawick et al., 1967), Ericksonian hypnotherapy (Bandler and Grinder, 1975b; Grinder et al., 1977) and most importantly, the cybernetic epistemology of Gregory Bateson (Bateson, 1972) can be found.

Although, NLP has boomed into one of world's most popular forms of interpersonal skill and communication training there is limited, sporadic literature in this field (Tosey P and Mathison J, 2003). These include education (Craft, 2001), training and development (e.g. Lee, 1993; Thompson et al., 2002; Trickey, 1997), faster learning (e.g. Sandhu, 1994; Stanton, 1994), counselling and psychotherapy (e.g. Geronilla, 1989), clinical psychology and hypnotherapy (e.g. Barnett, 1990; Field, 1990; Jupp, 1989) and management (e.g. Ashok and Santhakumar, 2002; Georges, 1996).

Bridging the gaps in literature, this evidence based pilot study analyses the efficacy of NLP in therapeutic setting for improving emotional state. Author finds this study as an useful addition to limited literature of NLP's efficacy as a therapeutic tool.

\section{Method}

\section{Participants}

A total of ten participants (four male and six female, age range 26-56 years) took part in this study. All Participants were self referred.

\section{Data Collection}

All participants were required to fill Depression Anxiety Stress Scale, the NLP Wheel of Life scale, subjective experience (brief description of how they feel) before and after therapy session. Depression Anxiety Stress Scale (DASS) is a 42 item self report instrument for measuring three related negative emotional states of depression, anxiety and stress. Change in score on each of three categories of DASS was analyzed by performing t-scores tests. NLP Wheel of Life Scale allows one to access whether too much focus is being put on one part of life and so neglecting others. NLP wheel of life assesses harmony and balance in life. The wheel is divided into sixteen sections with ranking 0-10 where 10 marks totally happy. There are many different variations of wheel of life and the one used in this study was divided into Health, Happiness, Giving Love, Receiving Love, Social Life, Partner, Living Environment, Energy, Sleep, Self Esteem, Confidence, Weight, Work, Money, Personal Development and Goals.

\section{Procedure}

NLP Psychotherapy techniques applied included rapport building, swish technique, anchoring, timeline based techniques, perceptual position, double dissociation technique, metaphors, value hierarchy elicitation, sub-modality change, parts integration, reframing, sleight of mouth patterns, compulsion blow out technique, strategy elicitation and change. Sequence and combination of NLP techniques for each participant was customized to best address to individual needs.

\section{Results}

Following tables and figure shows each participant's demographics, brief problem statement, psychotherapy technique/(s) chosen to suit each participant's needs, pre and post therapy score of all three categories of DASS. 
Table 1 shows participant details( Name Code, Age, Gender) with brief problem statement and NLP psychotherapy technique used. Table 2 shows progress of participants and subjective changes with time span of follow-up for each participant. Figure 1 shows score changes in each category of DASS (Depression, Anxiety, Stress Scale) pre and post therapy. Figure 2 (a) shows NLP wheel of life score before therapy and Figure 2 (b) shows NLP wheel of life score after therapy. Follow-up of resourceful state attained was done. Follow-up of up to six months was done. Out of all ten participants five participants retained positive outcome of therapy on emotional state for up to six months, two participants were available for follow-up of only three months and one month each and three participants could not be reached for follow-up. Statistical significant improvement $(\mathrm{p}<0.001)$ was observed on Depression Anxiety Stress Scale (DASS) for all three categories of stress, anxiety and depression. NLP wheel of life was also more balanced for each participant after therapy and resourceful subjective experience of participants was also noted.

Table 1: Demographics, brief problem statement with NLP Techniques chosen for each participant respectively

\begin{tabular}{|c|c|c|}
\hline $\begin{array}{l}\text { Participant } \\
\text { Code, Age, Gender }\end{array}$ & Brief Problem Statement & $\begin{array}{l}\text { NLP Psychotherapy technique } \\
\text { chosen }\end{array}$ \\
\hline $\begin{array}{l}\text { DuGe } \\
26 \mathrm{~F}\end{array}$ & Stress due to severe pigeon phobia & $\begin{array}{l}\text { Double dissociation technique: fast } \\
\text { phobia cure }\end{array}$ \\
\hline $\begin{array}{l}\text { PuUr } \\
44 \mathrm{~F}\end{array}$ & Stress in daily life and Snake phobia & $\begin{array}{l}\text { Double dissociation technique: fast } \\
\text { phobia cure combined with } \\
\text { reframing, sleight of mouth, time } \\
\text { based technique and metaphors. }\end{array}$ \\
\hline $\begin{array}{l}\text { ShRa } \\
56 \mathrm{M}\end{array}$ & $\begin{array}{l}\text { Panic attacks and anxiety after a } \\
\text { traumatic incident five year ago }\end{array}$ & $\begin{array}{l}\text { Time based technique and } \\
\text { anchoring }\end{array}$ \\
\hline $\begin{array}{l}\text { PuCh } \\
26 \mathrm{~F} \\
\end{array}$ & $\begin{array}{l}\text { Stress during driving and finds it hard to } \\
\text { remember route. }\end{array}$ & Metaphors and change in strategy \\
\hline $\begin{array}{l}\mathrm{MaAb} \\
30 \mathrm{M}\end{array}$ & $\begin{array}{l}\text { Limiting belief of being an unhappy } \\
\text { person, inefficient and unable to see } \\
\text { other's perspective leads to daily stress }\end{array}$ & $\begin{array}{l}\text { Value hierarchy elicitation, time } \\
\text { based technique, reframing, } \\
\text { perceptual position and metaphors }\end{array}$ \\
\hline $\begin{array}{l}\text { GrDa } \\
27 \mathrm{M}\end{array}$ & $\begin{array}{l}\text { Career stress due to limiting belief of } \\
\text { having poor communication skills. }\end{array}$ & $\begin{array}{l}\text { Values hierarchy elicitation, } \\
\text { compulsion blow out, reframing } \\
\text { and metaphors }\end{array}$ \\
\hline $\begin{array}{l}\text { MiAg } \\
42 \mathrm{~F}\end{array}$ & $\begin{array}{l}\text { Limiting belief of poor performance, } \\
\text { short temper }\end{array}$ & $\begin{array}{l}\text { Sub-modality change, anchoring, } \\
\text { time based technique }\end{array}$ \\
\hline $\begin{array}{l}\text { MsAt } \\
33 \mathrm{~F} \\
\end{array}$ & $\begin{array}{l}\text { Conflict in decision making } \\
\text { Weight Issues }\end{array}$ & $\begin{array}{l}\text { Parts Integration } \\
\text { Swish pattern }\end{array}$ \\
\hline DeAs & Difficulty moving On with & $\begin{array}{l}\text { Sub modality change for limiting } \\
\text { belief }\end{array}$ \\
\hline $40 \mathrm{~F}$ & life after a failed relationship & $\begin{array}{l}\text { change, metaphors, anchoring and } \\
\text { values hierarchy elicitation }\end{array}$ \\
\hline $\begin{array}{l}\text { SoRo } \\
34 \mathrm{M}\end{array}$ & $\begin{array}{l}\text { Stress of taking a decision at crossroads } \\
\text { of life }\end{array}$ & Parts Integration \\
\hline
\end{tabular}


South American Journal of Academic Research

Special Edition May 2016

Table 2: Experiential Progress of participants pre and post therapy session

\begin{tabular}{|c|c|c|c|}
\hline Participant & $\begin{array}{l}\text { No. of } \\
\text { sessions }\end{array}$ & Subjective report & $\begin{array}{l}\text { Progress } \\
\pm\end{array}$ \\
\hline DuGe & 1 & $\begin{array}{l}\text { Phobia extinguished. Helped a dying pigeon reach bird care } \\
\text { shelter some days after therapy session. } \\
\text { Six months follow up }\end{array}$ & + \\
\hline $\mathrm{PuUr}$ & 3 & $\begin{array}{l}\text { Phobia cured and handles stressful events in daily life } \\
\text { efficiently and with ease. } \\
\text { Six months follow up }\end{array}$ & + \\
\hline ShRa & 1 & $\begin{array}{l}\text { No Anxiety as observed in future pacing during session } \\
\text { No follow- up }\end{array}$ & + \\
\hline $\mathrm{PuCh}$ & 1 & $\begin{array}{l}\text { Enjoys driving and better at remembering routes } \\
\text { Six months follow up }\end{array}$ & + \\
\hline $\mathrm{MaAb}$ & 3 & $\begin{array}{l}\text { Better image of self and exploring new interests } \\
\text { Better at understanding other's esp. spouse/parents } \\
\text { perspectives } \\
\text { Practicing being relaxed and joyful } \\
\text { One month follow-up }\end{array}$ & + \\
\hline GrDa & 1 & $\begin{array}{l}\text { Reaching out in career opportunities with ease focusing on } \\
\text { individual strengths } \\
\text { Reported value hierarchy elicitation helps him progressively } \\
\text { in making satisfactory choices continually } \\
3 \text { months follow-up }\end{array}$ & + \\
\hline MiAg & 2 & $\begin{array}{l}\text { Feels Confident and better output at work } \\
\text { Anger issues resolved } \\
\text { Six months follow-up }\end{array}$ & + \\
\hline MsAt & 1 & $\begin{array}{l}\text { Was able to take decision in the therapy session } \\
\text { Confident to work at resolving weight issue } \\
\text { No Follow-up }\end{array}$ & + \\
\hline DeAs & 2 & $\begin{array}{l}\text { Joyful and Working towards self empowerment and life } \\
\text { enrichment } \\
6 \text { months follow-up }\end{array}$ & + \\
\hline SoRo & 1 & $\begin{array}{l}\text { Took decision in the session } \\
\text { No follow-up }\end{array}$ & + \\
\hline
\end{tabular}

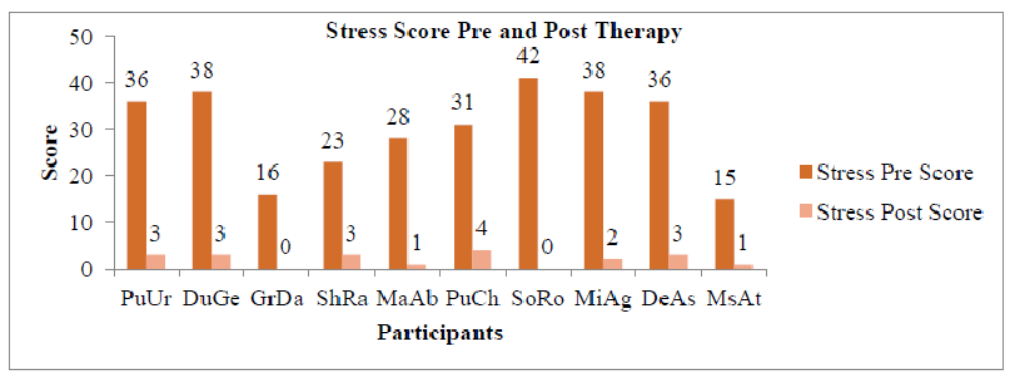

Fig 1(a) : DASS Stress Score Change 


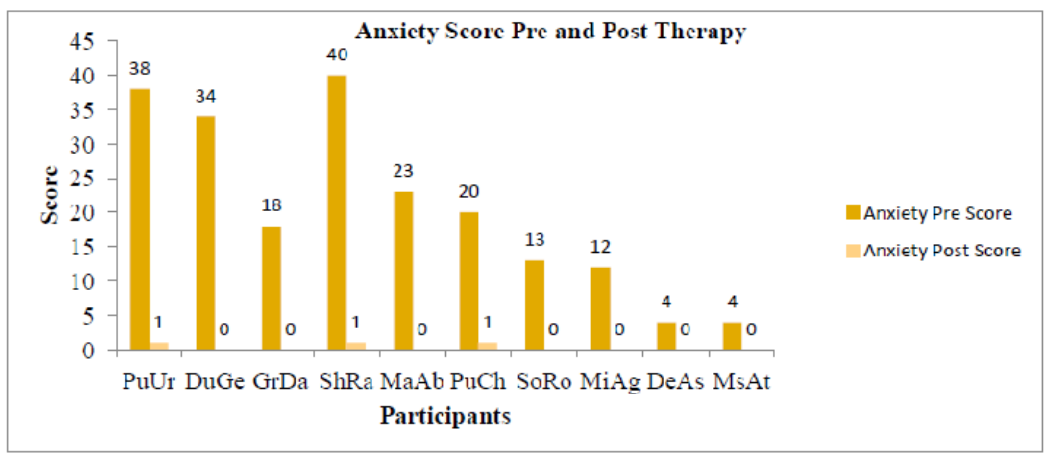

Fig 1(b) DASS Anxiety Score Change

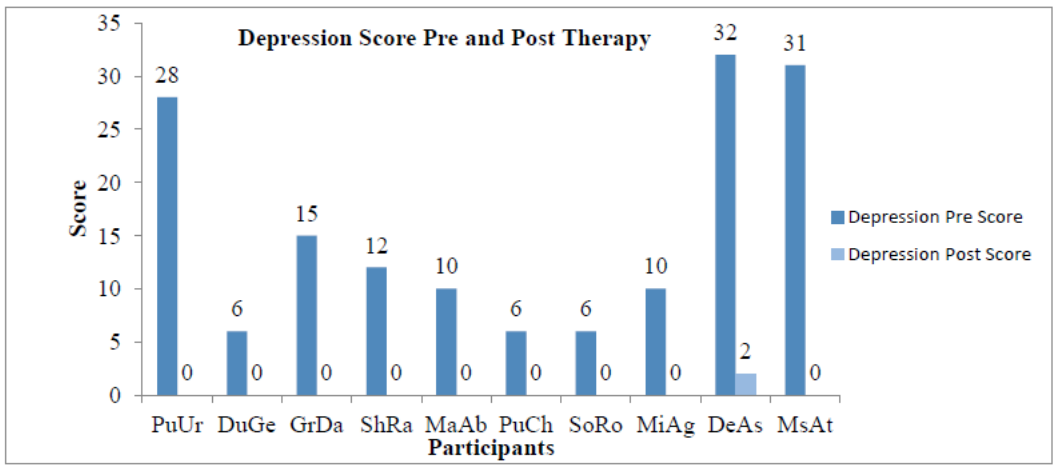

Figure 1(c) DASS Depression Score Change

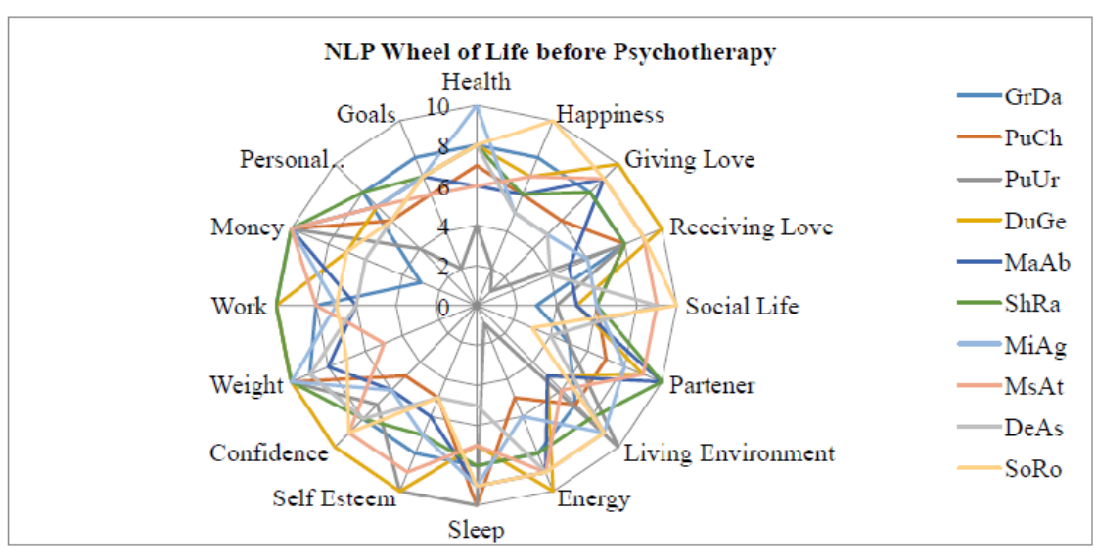

Figure 1: Graphical Analysis of Depression, Stress, Anxiety Scale Score Change 
South American Journal of Academic Research Special Edition May 2016

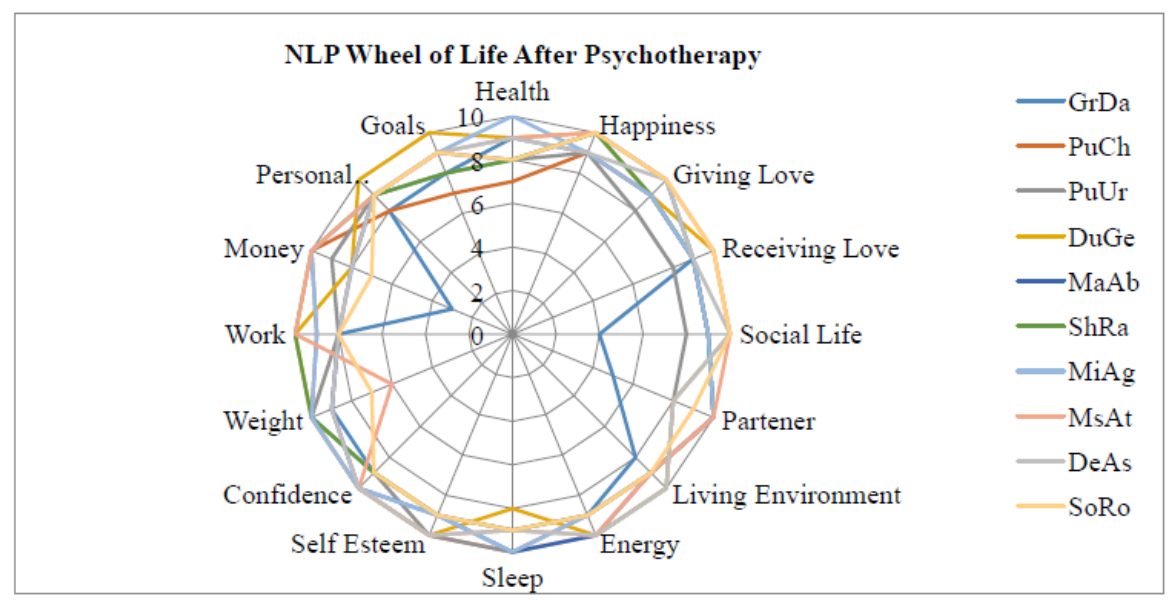

Figure 2 (a): NLP Wheel of life Scale. Each skewed circle represents a score of various categories for each participant before NLP Psychotherapy (b): NLP Wheel of life Scale. Each skewed circle represents a score of various categories for each participant after NLP Psychotherapy

\section{Discussion}

NLP Psychotherapy techniques used for emotional state improvement yielded positive progress reports in few sessions (maximum number of sessions required in this study was three where each session lasted for approximately sixty minutes). Improved emotional state is suggested by statistically significant improvement (p values $<0.001$ ) in all three categories of DASS along with more balanced wheel of life scale after NLP therapy session. Participants validated the statistical findings with experiential resourceful progress and follow up study of up to six months noted sustained progress.

\section{Conclusion}

Resourceful progress in emotional state was experienced by participants in brief duration. Statistically significant ( $p$ values $<0.001$ ) improvement was observed on scores of all three categories (Depression, Anxiety and Stress) of DASS along with improvement in wheel of life scale post therapy sessions. All these findings suggests that NLP Psychotherapy could be a viable option for people looking for sustained results for improving emotional state in lesser time.

However, it should be noted that NLP Psychotherapy is more dependent on how a technique is performed rather than which technique is used and success of therapy is greatly dependent on client- therapist rapport like in all therapeutic processes.

This pilot study shows positive findings and there is scope for further research. Author sees this study as an important addition to the limited database of NLP psychotherapy. This pilot study could be seen as an evidence based study which is supported by statistical analysis, subjective experiential changes and few months follow up of resourceful changes attained.

Author acknowledges that this study would have been better if sample size was larger with control study. This study reports preliminary results from an ongoing lateral study and further resources would be added in future. 


\section{References}

[1.] Ashby, W. (1965) An Introduction to Cybernetics. Methuen: London.

[2.] Ashok, S. and Santhakumar, A. R. (2002) NLP to promote TQM for effective implementation of ISO 9000. Managerial Auditing Journal, 17(5): 261-5.

[3.] Bandler, R. (1985) Using your Brain for a Change. Moab, Utah: Real People Press.

[4.] Bandler, R. and Grinder, J. (1975b) Patterns of the Hypnotic Techniques of Milton H. Erickson, M.D.

Vol 1. Cupertino, California: Meta Publications.

[5.] Bandler, R. and Grinder, J. (1979) Frogs into Princes: Neuro-linguistic Programming. Moab, Utah:

Real People Press.

[6.] Bandler, R. and MacDonald, W. (1988) An Insider's Guide to Sub-Modalities. Cupertino, California: Meta Publications.

[7.] Barnett, E. A. (1990) The contribution and influence of neurolinguistic programming on analytical hypnotherapy. Australian Journal of Clinical Hypnotherapy and Hypnosis 11(1): 1-14.

[8.] Bateson, G. (1972) Steps to an Ecology of Mind. London: Paladin/Granada.

[9.] Bolstad, R. (2002) Resolve: A new model of therapy. Crown House Publishing Ltd.

[10.] Craft, A. (2001) Neuro-linguistic Programming and learning theory. The Curriculum Journal 12(1):

125-36. NLP

[11.] Field, E. S. (1990) Neurolinguistic programming as an adjunct to other

psychotherapeutic/hypnotherapeutic interventions. American Journal of Clinical Hypnosis 32(3): 174-82.

[12.] Georges D.P. (1996) Improved employee selection and staffing through meta programmes. Career

Development International 1(5): 5-9.

[13.] Geronilla, L. (1989) Neuro-linguistic programming compared to reality therapy. Journal of Reality

Therapy 9(1): 13-19.

[14.] Gray R M, Liotta R F: PTSD: Extinction, Reconsolidation, and the Visual-Kinesthetic Dissociation Protocol. Traumatology 18(2) - SAGE journals: 3-16, 2012.

[15.] Grinder, J. and Elgin, S. (1973) A Guide to Transformational Grammar. New York: Holt,

[16.] Grinder, J., DeLozier, J. and Bandler, R. (1977) Patterns of the Hypnotic Techniques of Milton H.

Erickson, M.D. Vol II. Capitola, California: Meta Publications.

[17.] Jupp, J. J. (1989) Neurolinguistic programming: an experimental test of the effectiveness of "leading"

in hypnotic inductions. British Journal of Experimental and Clinical Hypnosis 6(2): 91-7.

[18.] Lee, A. (1993) Outdoor education and Neuro-linguistic Programming. Journal of Adventure

Education and Outdoor Leadership 10(4):16-17.

[19.] McWhirter, J. (1992) Sensory Systems Training Manual. Glasgow: Sensory Systems. NLP

[20.] Perls, F. (1969) Gestalt Therapy Verbatim. Moab, Utah: Real People Press.

[21.] Rogers, C.R. (1961) On Becoming a Person. London: Constable.

[22.] Sandhu, D. S. (1994) Suggestopedia and Neurolinguistic Programming: introduction to whole brain teaching and psychotherapy. Journal of Accelerative Learning and Teaching 19(3): 241-56.

[23.] Stanton, H. E. (1994) Suggestology and NLP: are there similarities?. Journal of Accelerative Learning and Teaching 19(3): 241-56.

[24.] Tabrizi F, Shafiabadi A, Zahrakar K. (2015) Investigation the effectiveness of assertiveness training using neuro-linguistic strategies (NLP) to reduce anger among married women. New York Science Journal 2015;8(1):64-72.

[25.] Thompson J.E., Courtney, L. and Dickson, D. (2002) The effect of neurolinguistic programming on organizational and individual performance: a case study. Journal of European Industrial Training 26(6):

292-8.

[26.] Tosey P. and Mathison J. (2003) Neuro-linguistic programming and learning theory: a response. The curriculum Journal Vol. 14 No. 3 Autumn 2003 pp 371- 388

[27.] Trickey, K. V. (1997) How information gathering works for the librarian or the personal development coach. Journal of Managerial Psychology 12(5): 352-6.

[28.] Wake L, Leighton M: Pilot study using Neurolinguistic Programming (NLP) in post-combat PTSD Mental Health Review Journal 19(4): 251-264, 2014.

[29.] Watzlawick, P., Beavin, J.H. and Jackson, D.D. (1967) Pragmatics of Human Communication. New York: Norton. 
South American Journal of Academic Research

Special Edition May 2016

\section{Author Note}

Chetna Punia is a student of Counseling Psychology at School of Behavioral Psychology, Texila American University, Woolford Ave, Georgetown, Guyana, South America

Chetna Punia is also a certified NLP Psychotherapist, NLP master practitioner and Advanced life coach trained under guidance of Dr. David Lincoln and Dr A. Doris Greenwood. This training is approved by ANLP (India).

Correspondence concerning this article should be addressed to Chetna Punia, School of Behavioral Psychology, Texila American University, Woolford Ave, Georgetown, Guyana, South America. Contact: chetna.punia@gmail.com 